\title{
An Analysis of the Effective Path of Life Education for College Students against the Background of "Internet Plus"
}

\author{
Kun Wang ${ }^{\mathrm{a}}$, Dong Yu and Jianlei Qian \\ Shandong University of Finance and Economics, Ji'nan, Shandong, China \\ a12602489@qq.com
}

Keywords: Internet Plus; college student; life education; effective path

\begin{abstract}
The Internet brings about convenience to college education, and at the same time puts forward new challenges for safety education of college students. In recent years, the psychological problems of colleges across the country have emerged in an endless stream, even suicide. This article starts with the related meaning of "Internet Plus" and life education, analyzing opportunities and challenges faced against the "Internet Plus" background, excavating the reasons behind, and proposing the effective path of college student life education against the background of "Internet Plus" from perspectives of individuals, colleges and the government.
\end{abstract}

\section{Introduction}

In recent years, some colleges have witnessed repeated security incidents, such as suicide, loss of association, kidnapping, and sexual assault. Tragedies have aroused widespread concern in the society and colleges. College students are the mainstay of social development and an important force to promote social progress. How to make students scientifically cognize and cherish life against the background of the Internet, seeking life meaning and value, achieving harmonious and healthy growth, structure urgent and major issues for colleges to study and solve.

\section{Meaning of "Internet Plus" and Life Education}

\subsection{Meaning of "Internet Plus"}

In November 2014, Premier Li Keqiang attended the first World Internet Conference. He pointed out the Internet served as a new tool for popular entrepreneurship and innovation. "Internet Plus" was first proposed in March 2015, representing a new economic form. It actually means the Internet plus traditional industries, but not simply joining them, relying on the platform of the Internet, applying various information and communication technologies such as mobile Internet, cloud computing, big data, intelligence, and the Internet of Things, integrating the Internet and traditional industries, creating new forms of social and economic development, realizing more functions and innovation, and further upgrading benefits of various industries.

"Internet Plus" can be applied to multiple fields, such as "Internet + Industry", "Internet + Finance" and "Internet + Education". Education against the background of "Internet Plus" mentioned in this article refers to the combination facilitating colleges and educators to apply education and Internet services for growth and development.

\subsection{Meaning of life education}

In 1968, Jay Downer Walter first proposed “Life Education”, a moral education focusing on educating students to respect human life, educating students to respect animal life, cultivating students for the long-term goal of sustainable development.

Different scholars have different views on the connotation of life education. In 2012, China Employment Training Technical Guidance Center vocational training course "Life Education Supervisor" pointed out, life education referred to the education of life and death, aiming to make people respect life and understand life significance, the relationship between life and universe, learning to actively survive, leading a healthy life, developing independently. Mutual life care, 
record, gratitude and share, achieving harmony physically and mentally, career success and life happiness and ultimately achieving the greatest value.

\section{Opportunities and challenges faced by college student life education against the background of "Internet Plus"}

\subsection{Opportunities faced by life education against the Internet}

\subsubsection{The Internet provides shared spaces to life education resources}

Against the Internet, information across the gap achieves synchronic delivery, breaking the closed and rigid situation of previous life education resource management. In the shared network, various forms of information from various channels are collected, even among teachers and students. Students and students, exchanges and interactions regarding life education are traceable. Sharing is available within a college, and various colleges in the country, even across national borders, even global life education resources are integrated and exchanged, ultimately forming a comprehensive coverage of the life education network. At the same time, the exchange of supply and demand information between different educational resources play a complementary role, and educators can learn from each other in experience for better life education.

\subsubsection{The Internet providing a new platform to life education}

First, the Internet can be used to establish online teaching centers to achieve seamless two-way exchange of educational activities in time and space, replacing passive one-way education. Moreover, educators and the educated have the same right to speak, making their communication intimate, equal and natural. In addition, new media provide new platforms to flexible development of life education. For example, QQ, We Chat and other instant messaging applications are applied for intimate interaction and exchange, achieving convenience and practicality of information transfer. Micro-blog and friend circles and other interactive platforms publish topics and forward comments or articles, achieving instantaneousness of information transmission. Various types of APP are applied to provide sound and video, achieving intuitiveness of information exchange. Powerful new media have made life education flexible and diverse.

\subsubsection{The Internet making life education people-friendly}

The virtual nature of the Internet helps concealing heuristic education, meeting individual needs of today's college students. Against the background of the Internet, life education is no longer forceful indoctrination. The virtual nature of the Internet has achieved invisible penetration of educational objects, making young people who are usually shy have subtle and private communication spaces. At the same time, college educators can apply their spare time to scientifically guide and educate students through enlightenment and inspiration, guiding their ideological awakening through graphics, web chat, and information review, solving difficulties and providing services to students for their growth.

\subsection{Challenges faced by life education against the Internet}

\subsubsection{Over-reliance on the Internet affecting physical and mental health}

The "excessive working” causes destruction and damage, affecting physical and mental health and even causing death. However, college students who are immersed in the virtual world of the Internet tend to consume their health. The Internet is in line with the novelty and trend some modern young people, especially college students. They often indulge themselves in the various temptations and become overly dependent on them. They severely disturb normal life and learning rhythms, physically overworked during long-term disturbances, resulting in decreased physical resistance and apathy, forgetfulness and other "excessive working". Moreover, some indulging college students are reluctant to walk out of a small space and constantly stay in places such as dorms, causing physical damage and serious mental loss, seriously affecting their growth. 


\subsubsection{Vicious incidents constantly increasing}

The inadequately regulated network environment has made the Internet a bane disseminating negative energy. "Blue Whale Game", the death game, was once popular among the global youth, making "suicide" a way to catch up with the "trend". Disappearance of young lives was the tragic results of the evil Internet. Internet security loopholes made lawbreakers generate illegal ideas. They stole information, mad up lies, fraudulently deceiving insufficiently self-protected college students, severely cracking down on their fragile minds, making some students vulnerable and harm themselves, causing illegal behaviors, such as illegal online sensation, sleazy live broadcasts, and campus nude loans. They seduced some students with interests, cheating and deceiving, confusing some students and making them corrupt, making vicious incidents constantly increasing.

\subsubsection{Colleges insufficient control of the Internet}

Life education in colleges can hardly keep up with changes in the Internet. It is difficult to develop a rational life education platform attracting students, resulting in a waste of life education resources. First of all, life education carried out by colleges through the Internet is seriously inadequate, lacking a proper life education atmosphere. The survey shows insufficient colleges carry out life education through the Internet. The development of life education through the Internet can not meet the needs of college students. In addition, some colleges suffer insufficient technology, making their education through the Internet formalized. Some colleges have their Internet platforms established simply for Internet based, lacking systematic teaching programs and professional teachers. Some interested students fail to consult. Life education in colleges seriously lacks death education, insufficiently making students focus on "cherishing life" and "establishing correct values”.

\section{Causes for challenges of life education against the Internet Plus background}

\subsection{Some college students suffer less resistance to the Internet temptation}

Some college students suffer improper awareness of negative effects of the Internet, indulging in unhealthy attitudes. Their ideology is not yet mature, with their outlook on life and values being shaped. Spreading of multiple values through the Internet make some unhealthy thoughts easily affect some students, leading to confusion of their values and even wrong ideas. They suffer weak values and insufficient consciousness, indifferent to some mental poisons like false news, various rumors, and irrationalities, prone to extreme behaviors and health and life dangers. At the same time, some students suffer poor dilemma self-repair ability. Facing Internet addiction, some students often lose self-control and have uncorrected laissez-faire behaviors, indulging in an entertaining and stimulating virtual world, playing with computers and mobile phones, relying on personal virtual world, facing normal interpersonal crisis, witnessing serious problems without rethinking, making the Internet murderous tools to avoid learning, become lazy and conduct cheating. Powerful functions of new media cause their excessive reliance, serious inertia, and serious reduction in ability to think and create. Over time, it will lead to degradation of thinking and a lonely and stereotyped dead end.

\subsection{Colleges attaching insufficient importance to Internet applications}

Some colleges fail to attach sufficient importance to life education, without offering life education courses, let alone applying the Internet to carry out life education. Some colleges attach importance to life education, but valuing their unique education systems and models. Against "Internet Plus" boom, they are often reluctant to change their thinking and develop new systems. Moreover, applications of the Internet require quite high capital investment and manpower, needing participation of life education experts and support of competent Internet technology personnel. Long-term and continuous investment requires professionals to constantly stand by to meet student inquiries and repair the network platform. In a word, colleges distrust the Internet and disagree with the input-output ratio cause insufficient importance to the application of the Internet, making it 
difficult to carry out life education through high-quality Internet.

\subsection{Insufficient supervision over the life education online platform}

Social supervision over the Internet environment is insufficient, making the Internet suffer ill information, seriously disrupting the application of college student normal networks, causing negative impact on their healthy growth. Global sharing of Internet information and its convenient search functions broaden horizons of students, meeting their needs for efficient and convenient access to large amounts of information. However, they also make it convenient for some harmful foreign institutions, making them spread some rotten and harmful materials and reactionary values. In addition, the Internet provides open and equal platforms. Almost everyone can publish information, providing certain opportunities to criminals to spread fraudulent information, violence, and pornography through the Internet. The Internet is emerging, and the state and government have not yet matured their supervision. The hidden nature of the Internet makes it more difficult for the government to supervise it. It is necessary for all walks of life to strengthen reporting of ill information through the Internet, stopping spread of ill information through the Internet, striving to reduce negative impact of the Internet on college students.

\section{The effective path to developing life education against the background of "Internet Plus"}

Considering opportunities, challenges and reasons behind faced "Internet Plus" era college student life education, it is necessary, significant and practical to continuously explore effective paths for life education against the background of "Internet Plus", exerting multiple resources, exploring and developing extensive, multi-perspective, sufficient "three-in-one" new life education model college students merging individuals, colleges and the government into a single whole, making students get rid of misunderstandings, correctly understand life value and meaning, cherish life, be friendly, promoting their harmonious development.

\subsection{College student self-identification and self-control improvement}

Students are the subjects of college life education. College teaching requires cooperation and support of students. Their self-identification and self-control guarantee smooth implementation of life education against the Internet. First of all, students should exert their self-learning subjective initiative, actively exploring correct three outlooks, establishing positive and progressive life goals. They should enrich themselves with books from college libraries, correcting their ideas through communication with teachers and classmates, establishing correct values to resist against foreign ill information. Second, they should remain open-minded, conducting mutual communication, actively participating in social and group activities, integrating into the collective, obtaining knowledge, broadening horizons, growing up in frustrations, enhancing resistance to pressure. Furthermore, they should apply the Internet as learning tools. They should understand the Internet is not only used for entertainment, but a platform for obtaining knowledge. They should actively participate in college online learning, providing prompt feedback to teachers about their problems, proposing the models for life education, making life education against the background of the Internet meet their needs, helping them with the problems related to life and health, and promoting their healthy growth.

\subsection{College improvement of the quality of life education against the background of the Internet}

As the main communicators of life education, colleges should exert their guidance and education roles, actively applying the Internet to improve the effectiveness and quality of life education. First, it is necessary to establish life education-related online communication and sharing platforms, special windows on life education on official websites, making them obtain relevant knowledge. At the same time, it is proper for them to apply We Chat, QQ, micro-blog, and even Baidu Post Bar and forums to establish interactive platforms. Second, it is necessary to expand life education activities against the background of the Internet, enriching teaching methods, applying diversified 
teaching methods to attract students, enriching teaching resources, allocating assistant Internet teachers, enhancing student sense of belonging, supplementing "tree hole" exchange windows, providing anonymous and confidential consulting platforms for shy students, conducting team competitions and other group activities, enhancing personal exchanges. Furthermore, it is necessary to professionally train life education teachers, making them competent to guide students. It is necessary to conduct regular assessments, examining teaching effects, strengthening supervision over teachers and teaching progress, providing quality life education. .

\subsection{The government development of the sound life education network environment}

With the popularity of Internet applications and increasing roles of the Internet in work, study, and daily life, it is necessary for the governments at all levels to gradually establish specialized Internet regulatory agencies to strengthen supervision over the Internet. First, it is necessary to strictly control all kinds of information published through the Internet, conducting rational classifications, preventing unintended spread of ill information. Second, it is necessary to strengthen the supervision over network information dissemination, prompt stopping its dissemination through the Internet. In case of fraud, pornography, and other ill information, it is necessary to immediately delete it and shut up relevant accounts, conducting repeated inspections and review of violations and illegal websites, preventing its proliferation and spread. Third, it is necessary to take legal means to strictly deal with violations of laws and disciplines. Relevant rules and regulations for the Internet and legal responsibilities shall be clearly stipulated by supervision authorities and legal organs. Violation of laws and disciplines shall be stipulated, and relevant principals shall be seriously dealt with in accordance with relevant regulations. At the same time, it is suggested that government organs should cooperate with all colleges, enhancing review of Internet education platforms, providing students with the green and healthy life education network environment.

\section{References}

[1] Ye Huasong, College Student Life Education [M] Zhejiang: Zhejiang University Press. 2011.6.

[2] Hu Jingxian. Study on Life Safety Education for College Students Based on Mobile Internet [J]. Journal of Heihe University, 2017(7)

[3] Zhang Lina, Study on Infiltration Life Education in Biology Teaching [J] New Curriculum (Middle), 2015 (12).

[4] Chen Guobei. Reflections on Problem Solving Path for Life Education for Post-90s College Students[J]. Education and Teaching Forum, 2014(6)

[5] Zhang Meiyuan, Improvement of Effectiveness of Contemporary Campus Life Education [J] Intelligence, 2015(27)

[6] Wang Zhiwei. Study on College Student Life Education against New Media: Based on Surveys in 3 Colleges in Hainan Province[D]. Hainan: Hainan Normal University, 2017.

[7] Li Huihua, Study on College Student Life Education Practice Activities in the Internet Era[J] Journal of Hunan Mass Media Vocational and Technical College, 2015(6).

[8] Nie Na., Study on College Student Life Education against the New Media Environment [D]. Shandong: Shandong University, 2017. 